\title{
IMPLICAÇÕES POSSÍVEIS DO TERMO WOHLGEFALLEN NA CRÍTICA DA FACULDADE do Juízo
}

\author{
[Possible implications of THE TERM WOHLGEFallen IN THE CRITIQUe OF THE POWER OF \\ JUDGMENT]
}

\author{
Leandro José Rocha * \\ Universidade Federal de Santa Catarina
}

\begin{abstract}
Resumo: Este artigo resgata o sentido comunitário do termo Wohlgefallen sugerido pelo correspondente latino complacere. Em Kant, há três modos de comprazimento: no agradável, nos juízos estéticos e no bom. Pela definição no início da $K U$ o agradável não possui relação com uma conotação comunitária. Ciente disso busca-se neste artigo investigar a possibilidade e limites de aplicação do sentido comunitário de comprazimento quando em ocasião do agradável visando o sentido da expressão comprazimento no agradável.
\end{abstract}

Palavras-Chave: Comprazimento. Prazer. Natureza. Kant.
ABSTRACT: This paper rescues the community sense of the term Wohlgefallen suggested by the Latin correspondent complacere. In Kant, there are three modes of complaisance: the cases of the agreeable, the aesthetic judgments and the good. By the definition at the beginning of the $K U$ the agreeable has no relation with a communal connotation. Aware of this, this article seeks to investigate the possibility and limits of application of the community sense of complaisance when on occasion of the agreeable, aiming at the meaning of the expression complaisance in the agreeable.

KEYwords: Complaisance. Pleasure. Nature. Kant.

\section{INTRODUÇÃo}

G ste artigo se originou de um problema que reconheci a partir de desdobramentos de uma nota de rodapé de Rohden, relacionada ao termo Wohlgefallen na $K U$. Trata-se de um esclarecimento do tradutor com relação à complacência, sua opção de tradução, que, segundo Rohden, teria o "sentido de comprazer, do latim complacere $=$ cum alio placere $[. .]=$. agradar a muitos"1, vinculando esse conceito a um prazer em um sentido comunitário, ou ainda, como menciona Rohden na nota geral sobre a tradução da KU, "no sentido de um prazer compartilhado"2. Nas rápidas notas ele não desenvolve (e entendo que não era o espaço para isso) uma explicação referente a possíveis implicações dessa característica do conceito, com o significado sugerido por ele, nos três modos de complacência/comprazimento (Wohlgefallen) ${ }^{3}$.

Meu interesse se deu basicamente tendo em vista que essa noção de

* Professor e pesquisador, doutor em Ontologia pela Universidade Federal de Santa Catarina (Florianópolis/Brasil). Este artigo contou com o apoio da CAPES - Proc. $n^{o}$ 4283/14-7.m@ilto: r.leandro@live.com 
comprazimento como um prazer compartilhado faz sentido facilmente no que concerne ao comprazimento nos juízos estéticos e também nos juízos morais, uma vez que em ambos os casos remete-se a uma universalidade dos juízos. Contudo, essa referência a um sentido comunitário, a um prazer que, por definição não seria meramente privado, entendo que pode apresentar uma dificuldade na compreensão da aplicação do conceito de comprazimento ao caso do agradável, uma vez que, no deleite, trata-se de um prazer na sensação, privado. Não obstante, Kant aplicou o termo comprazimento, que Rohden entende como remetido a um sentido comunitário, também ao caso do agradável.

Nesse sentido, o problema presente pode ser exposto do seguinte modo: diante da conotação comunitária sugerida para o termo Wohlgefallen e da definição de agradável implicando um prazer privado ${ }^{4}$, como ainda é possível se falar em termos de comprazimento no agradável? Minha preocupação de fundo despertada após lida essa observação de Rohden perpassa por questionar também: o que faz com que sintamos prazer ou desprazer com uma representação? Qual o critério para que uma representação seja sentida de um ou de outro modo (prazerosamente ou desprazerosamente)? Longe de dar uma resposta que satisfaça completamente o leitor deste artigo sobre esses questionamentos, permito-me aqui ao menos contextualizar melhor esse problema e apontar alguns caminhos por onde penso que a resposta pode seguir.

Em suma, minha proposta perpassa por sugerir a compreensão de se pensar enquanto hipótese que o que se sente com uma representação não é sentido como um prazer ou como um desprazer por um mero acaso e sim é sentido prazerosamente ou desprazerosamente a partir de um critério como implicação de um plano da natureza. Sugiro pensar como se a natureza do animal (racional e irracional) seja de tal forma que tende a premiar o corpo quando em situação que concorde com uma perspectiva e punir o corpo quando essa situação não concordar com essa perspectiva. Qual seria essa perspectiva, esse critério? Visando ao quê? Os três modos de comprazimento, ao entrarem em contradição, ainda assim estariam de acordo com esse plano? E, ainda, é possível pensar em tal organização da natureza? Aqui estará em defesa o sentido universal, coletivo do termo comprazimento também aplicado ao caso do agradável.

\section{Problemas de tradução}

Na Reflexão 567 Kant menciona que tudo o que promove o sentimento de vida apraz [gefällt] e, apesar de, no $\S 5$ da $K U$, Kant diferenciar os modos de comprazimento reservando, a rigor, o termo Gefallen apenas ao modo de comprazimento relacionado ao belo, ele se refere no $\S 3$ e no $\$ 4$ aos casos do agradável e do bom também relacionando ao Gefallen. Somente no $\$ 5$ ele faz a relação entre o deleite e o agradável; entre o aprazimento e o belo; entre a estima/aprovação e o bom; em uma comparação entre os três modos especificamente diversos de comprazimento, que é, por sinal, o título desse parágrafo.

Nesse parágrafo mencionado, Kant diz que "não são idênticas as expressões que convêm a cada um e com as quais se designa o comprazimento nos mesmos" ${ }^{5}$. Essa distinção é, pois, o motivo de meu estranhamento com relação a algumas sugestões de tradução do termo Wohlgefallen, quando vertidos de textos kantianos e cujo correspondente na língua de chegada reduz o sentido de Wohlgefallen a um dos modos de comprazimento. 
A rigor, pelo uso de Kant, penso haver apenas uma dessas reduções que seria aceitável. Diante da $K U$, entendo que o termo Wohlgefallen, a rigor, não pode ser traduzido por algum que corresponda apenas ao sentido que ele deu ao que traduzimos em língua portuguesa como deleite, como estima/aprovação, e também como comoção. Nesse momento do texto da $K U$, o último dos termos ainda não havia sido incluído. Tendo em vista os parágrafos do $\S 2$ ao $\S 5$ da $K U$, parece-me que Wohlgefallen pode ser entendido em uma perspectiva mais ampla, que inclui os três modos de prazer. Ou, ainda, o deleite, o aprazimento e a aprovação no bom são modos de comprazimento. Se essa compreensão estiver correta, então se pode considerar como insuficientes para correspondentes ao termo Wohlgefallen termos que se referem a espécies de Wohlgefallen. Ou seja, todo Vergnügen é Wohlgefallen, mas nem todo Wohlgefallen é Vergnügen.

Talvez se possa, em um uso menos preciso do termo, ser traduzido pelo mesmo termo utilizado no idioma de chegada para o correspondente escolhido para traduzir o termo Gefallen, uma vez que o próprio Kant utiliza, por vezes, o termo Gefallen com o sentido de Wohlgefallen, em uma abordagem que não se refere ao modo de comprazimento inerente ao belo, mas, inclusive, ao comprazimento como um grau mais elevado desse sentimento (Gefallen), aplicando-o aos casos do agradável, e do bom (também do sublime, mas, nesse caso, tal uso não causa estranheza). Entendo, assim, o Wohlgefallen, como um grau mais elevado de Gefallen, que é inclusive uma abordagem sugerida por Adelung, cujo Grammatisch-Kritisches Wörterbuch der Hochdeutschen Mundart ${ }^{6}$ teria sido utilizado pelo próprio Kant ${ }^{7}$. Sugiro, pois, que o termo Wohlgefallen pode ser entendido como se referindo, em Kant a uma totalidade dos modos de prazer, incluindo, pelo exposto no início da $K U$, o deleite, o aprazimento, a comoção e a aprovação. Ou, ainda, cientes de que não há outros modos de prazer além desses.

Paul Guyer e Eric Matthews (KU - Cambridge Edition) optaram por traduzir Wohlgefallen como satisfaction e Gefallen como please, opção essa que parece não possuir uma relação como sugiro considerar entre Wohlgefallen e Gefallen. James Creed Meredith (KU - Oxford Edition) optou por traduzir Wohlgefallen como delight e Gefallen (na maior parte das vezes) como please. Tendo-se em vista que o prazer da sensação é Vergnügen, em português Rohden optou para correspondente o termo deleite. Utilizando delight para Wohlgefallen, o que também o faz Howard Caygill ( $A$ Kant Dictionary), no caso de Meredith restou para Vergnügen o termo gratification. No caso de Caygill, além de delight, também se refere a Wohlgefallen como satisfaction. Tendo-se em vista o compartilhar do mesmo idioma, interessa-me mencionar Antônio Marques, que além de fazer constar como corresponde a Wohlgefallen, o termo comprazimento na versão lusitana da $K U$, faz ainda outras sugestões de tradução para esse termo. Em um artigo em língua inglesa (Kant's Third Critique: What the Concept of 'Gemüt' Brings to the Concept of Reason), Marques utiliza como tradução de Wohlgefallen para aquele idioma os termos delight e complaisance.

Entendo que complaisance possa ser entendida como uma opção deveras adequada, tendo-se em vista que Kant por algumas vezes utilizou termos como complacentia e mesmo Complacenz com o sentindo de Wohlgefallen, em passagens como, por exemplo, $\S 5$ da $K U, \S 69$ da Antropologia, ou ainda na Reflexão 1040. Os termos Complacenz und Displicenz ou ainda complacentia und displacentia são usados por Mrongovius (no livro 28, páginas 1265, 1275 e 1278) em um contexto que possibilita sugerir a compreensão de que podem corresponder a prazer e desprazer, principalmente, tendo-se presente o uso em Kant dos termos Lust und Unlust na Introdução à $K U^{8}$.

Como se sabe, em decorrência da pouca tradição à época de Kant de redação de 
textos filosóficos em alemão (o usual era o latim), não raro aos termos caros a Kant ele fez constar o correspondente latino. Com essa observação menciono que pode ser discutível se no alemão hodierno o termo Wohlgefallen manteve relação com o sentido do termo latino utilizado por Kant como correspondente. Contudo, por mais que talvez não se entenda hoje, de pronto, Wohlgefallen em um sentido comunitário, pode-se ainda justificar tal problemática do artigo pela recorrência ao termo latino registrado por Kant ao lado de Wohlgefallen, como o fez Rohden na nota já citada.

Uma vez que em língua portuguesa tem se utilizado como correspondente ao termo Gefallen o termo aprazimento, e tendo-se em vista o exposto, optei por utilizar ao longo desse artigo para correspondente ao termo Wohlgefallen o termo comprazimento, como já o fez Marques. Marques considera que a distinção em tipos de comprazimento implica em uma legitimação do elemento prazer como transcendental, visando uma proposta de sugerir universalidade ao prazer, mesmo sendo um sentimento ${ }^{9}$. Rohden optou por traduzir Wohlgefallen por complacência na Crítica da Faculdade do Juizo, não sem antes fazer constar uma nota explicativa na versão brasileira, da qual destaco, por ora, sua observação de que "a tradução proposta expressa o pensamento original de Kant, não obstante o seu difundido sentido pejorativo em português" 10 .

Sabe-se que Kant mesmo denunciava a degeneração de sentido de alguns termos e em algumas passagens chama a atenção para essa mutação de sentidos "devido a um longo uso equivocado"11. A opção de Kant nessas situações parece ser a de determinar o sentido apropriado do conceito e conservar a expressão ${ }^{12}$. Contudo, esse sentido pejorativo já anunciado por Rohden que o termo complacência tem em língua portuguesa é, no entanto, o motivo pelo qual eu optei por utilizar o termo comprazimento, entendendo que comprazimento é também adequado e, além disso, não carrega tal carga pejorativa que acompanha complacência devido a um longo uso equivocado desse último. Reconheço, no entanto, que em um uso preciso da linguagem a opção complacência seria muito adequada desde que os leitores entendessem de pronto o sentido original do termo ou, então, que tivessem condições de acompanhar a elucidação do conceito antes de seu uso. A mesma opção de Rohden é a de Artur Morão ${ }^{13}$. Em uma publicação póstuma de Rohden, Wohlgefallen aparece agora, mas não em todos os usos no mesmo texto, como satisfação: "um termo importante [...] presente em toda forma de apetição, é o da 'satisfação' (Wohlgefallen/Lust) ou do prazer"14. Em seus escritos da década de 70, Rohden também já abordou Wohlgefallen como satisfação ${ }^{15}$.

\section{TRÊS MODOS DE COPRAZIMENTO}

Na mesma nota de rodapé já citada da versão brasileira da $K U$, Rohden menciona que "ao gênero da complacência, equivalente a Lust (prazer), pertencem as espécies chamadas Geschmack (gosto) [...] e Vergnügen (deleite)"16. Concordo que o comprazimento possui íntima relação com o $\operatorname{prazer}^{17}$, bem como, os termos complacentia e mesmo Complacenz por vezes aparecem com um sentido que pode ser remetido não apenas a Wohlgefallen mas também a Lust. E, além disso, o texto kantiano parece chegar a considerar, em resumo, o prazer e o desprazer como o único sentimento possível $^{18}$, e isso talvez possa estar vinculado com a consideração de que haveria apenas um princípio imaterial no animal ${ }^{19}$. Para além dos modos de comprazimento, a discussão parece remeter a um e mesmo sentimento. Remetido a esse fundo comum básico, parece ficar claro o que pode levar comentadores a abordarem como equivalentes o prazer e o comprazimento. Nesse caso, sim, seria ocasião salutar para 
abordar como equivalentes o comprazimento e o prazer. Mas entendo que, a título de prudência, tal equivalência poderia ser sugerida após uma detida exposição de discussões inerentes ${ }^{20}$.

Afinal, a divisão entre modos de comprazimento não é uma divisão banal. Tal distinção é significativa em sua teoria, a descoberta de uma autonomia do prazer, em especial pela sua não vinculação com a faculdade apetitiva, com a qual até a segunda Crítica parece estar atrelada e vinculada a uma perspectiva de demérito. Como para uma faculdade de apetição autônoma Kant desvinculou-a do prazer, para um prazer autônomo parece ser um caminho necessário sua desvinculação da faculdade apetitiva e o descobrimento assim de um prazer desinteressado que não está mais atrelado à satisfação de um interesse, e sim ao pressuposto de uma conformidade a fins. Não se entende mais que o sentimento de prazer ou desprazer com uma representação se dá somente em decorrência da saciedade de um interesse e sim, agora, também porque essa representação que é experenciada pelo sentinte é conforme a fins. Kant distinguiu uma faculdade de apetição independente do prazer, bem como distinguiu um prazer desvinculado da faculdade de apetição - "condição necessária para [...] poder falar de moralidade ou de gosto"21.

No $§ 5$ da $K U$, Kant menciona que o agradável (das Angenehme), o belo (das Schöne), e o bom (das Gute) são três modos diversos de relações entre representações e o sentimento de prazer e desprazer ${ }^{23}$. Segundo Kant, "poder-se-ia dizer do comprazimento que ele, nos três casos mencionados [do agradável, do belo e do bom], refere-se a inclinação [Neigung] ou favor $[\text { Gunst }]^{24}$ ou respeito $[$ Achtung]"25. Assim, talvez mais propício para facilitar a compreensão da discussão seja salientar as condições a partir das quais se dá o prazer, tendo-se em vista a relação com o interesse, que me parece ser um critério a mais para distinguir entre as espécies de prazer. Deleite, aprazimento, aprovação e outros a partir de diferentes graus, como o gozo que é entendido como o íntimo do deleite, seriam espécies de prazer. O comprazimento pode ser entendido, no entanto, não como uma das espécies de prazer, e nem como simples sinônimo de prazer, mas, talvez, como um grupo que engloba os modos de prazer, ou, ainda, tendo-se em vista um esclarecimento sobre um possível sentido do prazer no corpo do animal.

As condições a partir das quais se dá o prazer, que se diferenciam tendo-se em vista basicamente o interesse e o desinteresse na existência do objeto de representação, possibilitam que se fale em modos de prazer. Diz-nos a $K U$ que "em referência ao sentimento de prazer, um objeto deve contar-se como pertencente ao agradável, ou ao belo, ou ao sublime, ou ao bom (absolutamente)" 26 . No caso de pertencer ao agradável, o modo de comprazimento específico é o deleite (Vergnügen), no caso do belo é o aprazimento (Gefallen), no do sublime é a comoção (Rührung) ${ }^{27}$, e no do bom, segundo a $K U$, é a aprovação (Billigung). Aqui, mais do que a sugestão de quais seriam nomeadamente as espécies de comprazimento em cada um dos modos, o que destaco no mencionado é que o objeto ou deve contar-se como pertencente ao agradável, ou ao belo, ou ao sublime, ou ao bom, ou seja, talvez todas as variações do sentimento de prazer e de desprazer estejam contempladas nesses quatro casos, mesmo que aqui não mencionadas.

Entendo não ser propício se deter numa supervalorização da menção a essas espécies de prazer pela nomenclatura delas, que, na $K U$ parecem seguir uma referência mais precisa (deleite, aprazimento, comoção e aprovação), uma vez que em outros textos, em especial nas Reflexões, mas também destaco na Metafísica dos Costumes e na Antropologia, Kant, apesar de se referir às mesmas espécies de prazer, não o faz com essa nomenclatura específica. Contudo, mesmo em passagens nas quais Kant parece 
não ser tão preciso na nomenclatura dessas espécies de prazer, utilizando por vezes expressões como prazer da inclinação, prazer contemplativo, entre outros, a caracterização da espécie de prazer permanece a mesma, os modos de comprazimento permanecem os mesmos.

Cito, por exemplo, a classificação na Introdução à $M S$. Na $M S$, os modos a partir dos quais se sente o prazer remetem à mesma abordagem da $K U$. A caracterização das espécies de prazer é dada a partir da vinculação ou não do prazer com interesse na existência do objeto. No caso de haver essa vinculação, trata-se de prazer prático. No caso da espécie de prazer desinteressada da existência do objeto, trata-se de prazer contemplativo. O prazer prático, ou ainda, as espécies de prazer que possuem relação com interesse na existência do objeto (todo interesse implica prazer, mas o prazer não implica interesse) é dividido ainda em duas espécies, tendo-se em vista por critério o prazer preceder a apetição (interesse da inclinação) ou ser efeito dela (interesse da razão $)^{28}$. Saliento que, nos parágrafos iniciais da $K U$, Kant também dá importância à relação entre o interesse na existência do objeto com as espécies de prazer, mas nomeia as espécies de forma mais precisa, conforme já mencionado.

\section{A RELAÇÃo ENTRE O PRAZER E A VIDA}

Apesar da divisão entre modos a partir dos quais se dá as espécies de prazer, o prazer pode ser considerado como um e mesmo sentimento, independente do contexto a que ele está atrelado. Refiro-me aqui a uma interpretação possível de que a vida em Kant pode ser compreendida como se estivesse relacionada com uma capacidade básica da alma de determinar suas forças. A alma sente uma representação enquanto representação, quer sejam representações apenas sensíveis, quer sejam representações totalmente intelectuais ${ }^{29}$. "Diante" dela, a alma determina suas forças para manter a presente representação ou dispersá-la. Na corporalidade do animal, tal efeito da alma é sentido como prazer e como desprazer. O prazer e o desprazer só é possível ser sentido no corpo animal ${ }^{30}$, o prazer e o desprazer é, assim, saindo um pouco da terminologia kantiana, apenas um sintoma, uma expressão da vida. Prazer e desprazer é aquilo que pode ser sentido da vida e só o é possível ser sentido pelo próprio sujeito vivo. A vida, assim, pensada como uma ação (determinação das forças por parte da alma) de acordo com as representações, não implica causar o objeto das representações, em produzir o objeto ou a ação, ou mesmo não implica movimento, para usar um termo amplamente atrelado a esse debate. Bem como, o prazer não possibilita conhecer nada do objeto relacionado à representação em relação à qual a alma se "posicionou" para mantê-la (a representação) ou dispersá-la.

Nesses termos, se no fundo trata-se de manter o estado atual (prazer) ou sair desse estado atual (desprazer), ou seja, se no fundo trata-se de um e mesmo sentimento, talvez haja quem questione por motivos em optar por um prazer de ordem mais nobre em detrimento de um prazer animal. Contudo, esse questionamento não se insere em uma perspectiva kantiana, porque não é pelo prazer que se age moralmente. Bem como, não é pelo tanto de prazer que se sente é que se mede o valor de uma vida ${ }^{31}$. A destinação do ser humano e mesmo dos animais irracionais parece não estar em sentir prazer ou dor. O prazer é apenas uma artimanha da natureza em nós. Segundo Kant, "tendo dado ao homem a razão e a liberdade da vontade que nela se funda, a natureza forneceu um claro indício de seu propósito"32.

Como se sabe, o homem "não deveria ser guiado pelo instinto"33, mas, também, "a natureza não faz verdadeiramente nada supérfluo e não é perdulária no uso dos meios 
para atingir seus fins" 34 . Ainda segundo Kant, "um órgão que não deve ser usado, uma ordenação que não atinja o seu fim, são contradições à doutrina teleológica da natureza"35. Entendido nesses termos, porque não seria contradição ter uma constituição tal que possibilite um deleite no agradável, por exemplo, se isso fosse apenas supérfluo, sem propósito algum, ou, ainda, se aquela situação deve de todo ser evitada em prol do agir moral? Se for contra o plano da natureza, por que então a natureza nos constitui dessa forma, em que em situação do agradável sentimos prazer? Para uma punição constante no exercício da privação? Seria esse o plano para o ser humano? Uma constante privação, luta contra sua animalidade, uma consciência dividida, tendo por causa "a compreensão da existência de uma subjectividade livre, mas sensível, racional, mas limitada"36? A destinação do homem é a insatisfação?

O homem não é apenas um espírito, uma cabeça de anjo alada, um ser de natureza imaterial dotado de razão. É também corpo material. Os obstáculos e promoções à vida que devem ser buscados na ligação entre o ânimo (a alma) e o corpo perpassam por experiências de prazer e de desprazer, que é o que se pode sentir da vida, e que, como já mencionado, estão relacionados com as representações, que despertam uma ação (uma determinação das forças) da alma diante de uma representação para mantê-la ou rejeitá-la.

Mais do que um fator complicador no homem (dotado de um corpo material) aspirando a dar ouvidos à razão, a uma ação moral, o sentimento de prazer e desprazer pode ser entendido como aquilo que está relacionado de forma necessária com a própria possibilidade de sentir-se vivo. Sem prazer ou desprazer, diz-nos a $K U$, o sujeito pode, no máximo, chegar a ter consciência de existência, mas não sentimento de vida. E isso não é por mero acaso, ou, ainda, o prazer em uma representação não se dá sem um critério. Estou a salientar aqui a condição a que está submetido o ser humano em sua complexa e obscura relação alma e corpo, a desembocar nos três momentos relacionados com a possibilidade de um sentimento de vida, nos três modos de comprazimento, a saber: no agradável, nos juízos estéticos e na ação moral. Sem o sentimento de prazer e desprazer não há como se sentir vivo.

Segundo Rohden, "a moralidade, do modo como é entendida por Kant, vinculase necessariamente com a vida e com o prazer" ${ }^{37}$. Nesse sentido, essa relação entre o prazer e a moralidade pode chegar a "surpreender interpretações distorcidas da filosofia moral kantiana"38. De qualquer modo, sobre a vinculação entre prazer e vida (e não apenas de uma ou outra espécie de prazer com a vida), Kant mesmo chega a mencionar, na Reflexão de número 4857 (1776 - 1778), que "unicamente prazer e desprazer constituem o absoluto, porque eles são a própria vida" 39 . Entendo que tal expressão, absoluto, pode remeter a um duplo sentido, já alertado por Kant na $\mathrm{Kr} V$, sentidos esses, a saber, para indicar que "algo é válido a respeito de uma coisa em si mesma"40 ou ainda "para indicar que algo é válido em todos os aspectos (ilimitadamente)" 41 . O filósofo explicitamente se declara a favor do uso do segundo sentido, ao menos naquela ocasião do contexto da $K r V$. A mesma opção de sentido feita por Kant para o termo é a adotada por Manuel Ferreira para interpretar a Reflexão 485742. O que quero salientar dessa passagem é a vinculação da vida ao prazer, em uma abordagem que remete a uma amplitude, em todas as relações, de modo incondicionado, ou, ainda, o prazer constituiria o incondicionado por ser a própria vida.

Tendo em vista o problema que provocou o presente artigo, quero a partir desse ponto dar prioridade para a perspectiva que considero pouco explorada, uma conciliação do prazer animal com o plano oculto da natureza, ou, ainda, o prazer e o desprazer com uma representação como orientados por algum critério, que outro não é do que a própria concordância da representação com o plano oculto da natureza. Sobre 
esse ponto, pensa-se como se a natureza, na constituição do animal, tivesse inserido nele as disposições naturais, bem como, no caso do ser humano, também a razão, o que pode dar uma noção de linhas gerais desse plano oculto da natureza, ou ainda, segundo Kant, um claro indício desse plano. Entendo que nesse constante jogo entre o prazer e o desprazer que constitui a vida do animal para Kant, é a concordância da representação com o plano oculto da natureza o critério para que a representação seja sentida como um prazer e que concilia o sentido abordado no início do artigo sobre o termo comprazimento com o caso do agradável, mesmo esse sendo um prazer por definição não comunitário.

\section{VIVER EM CONFORMIDADE COM A NATUREZA ${ }^{43}$}

Na Observação Geral sobre a Exposição dos Juízos Reflexivos Estéticos, ao comentar a teoria fisiológica do belo e do sublime de Edmund Burke, Kant sugere: "o ânimo/alma é por si só inteiramente vida (o próprio princípio vital), e obstáculos ou promoções têm que ser procurados fora dela e contudo no próprio homem [...] na ligação com seu corpo"44. A partir dessa citação, saliento a identificação do ânimo como princípio vital, a qual relaciono com a consideração de que uma das capacidades originárias da alma ${ }^{45}$ seria a de sentir e cuja atividade consistiria na iniciativa da alma em manter a representação ou dispersá-la, que no corpo remete ao jogo entre desprazer e prazer. Sobre esse ponto, Rohden menciona que "Kant, em dois contextos diversos da estética e da virtude - vincula a alma ou o ânimo com a vida corporal"46. Eu, no entanto, entendo que tal vinculação se dá também no contexto de uma perspectiva mais básica no animal, nomeadamente no caso do agradável.

Outra observação que quero mencionar ainda sobre aquela citação é a de que tanto os obstáculos quanto as promoções à vida devem ser buscados na relação do ânimo com o corpo. Sobre esse segundo ponto, Rohden menciona que "podemos dizer que tudo o que se opera no ânimo como princípio de vida corresponde a uma ideia plena de vida que procura realizar-se, inclusive, corporalmente" 47 . Essa passagem de Rohden, restrita a uma menção anterior do contexto estético e da virtude, amplio a um contexto meramente animal, entendendo por ânimo, na citação, a alma, mesmo na citação de Rohden. Assim, entendo que se fala do que se opera na alma como princípio de vida. Pois bem, retomando a perspectiva da função da alma na atividade relacionada ao sentimento de prazer e de desprazer, seria esse o princípio de vida, entendido como a atividade, que segundo Rohden corresponde a uma ideia plena de vida que procura realizar-se inclusive corporalmente, consideração essa com a qual, desse modo mais amplo, concordo. Saliento também a menção à consideração de uma ideia plena de vida, que remete a algo para além do mero animal que sente.

José Heck, em um debate distinto (referente ao suicídio e natureza humana), comentando sobre uma compatibilização de perspectivas animais com questões morais em referência aos "deveres para consigo mesmo" na $M S$, menciona que "o primeiro princípio consiste na máxima de viver em conformidade com a natureza, ao passo que o segundo equivale à máxima de fazer-se mais perfeito do que a simples natureza nos fez"48. Contudo, se entendermos que fazer-se mais perfeito do que a natureza nos fez também faz parte da destinação do homem, talvez isso também possa ser entendido com viver em conformidade com a natureza, estaria de acordo com a ideia que serve de fundamento para a natureza.

$\mathrm{Na}$ Reflexão 6658, Kant nos diz: "viver em conformidade com a natureza não significa viver segundo os impulsos da natureza mas segundo a ideia em que se 
encontra o fundamento da natureza"49. A partir disso, Rohden destaca a perspectiva de que "viver de acordo com a natureza quer dizer viver segundo uma ideia que serve de fundamento à natureza"50. Na sequência, complementa que "a ideia de natureza significa, pois, a natureza pensada no seu todo e não em suas especificações ou em seus impulsos"51. Rohden parece priorizar o aspecto racional envolvido, o ser humano, parecendo remeter o todo da vida ao todo dos homens, enquanto esses recusam as inclinações ${ }^{52}$. O que eu quero aqui priorizar é justamente a perspectiva dos impulsos e pensar uma conciliação também dessa perspectiva com o todo, com a ideia que serve de fundamento à natureza, ou seja, eu estou mais preocupado em discorrer acerca de uma hipótese para que sintamos prazer no agradável, uma vez que as demais situações de prazer parecem ser compatíveis com um plano da natureza.

Remetendo ainda à citação da Reflexão 6658, considero salutar fazer duas observações referentes à minha compreensão do citado, uma referente ao limite da compatibilização de impulsos da natureza com o fundamento da natureza, e a segunda referente ao mérito do próprio homem para se manter em conformidade com o fundamento da natureza na própria recusa em se deixar guiar pelos impulsos da natureza. Ambas serão desenvolvidas nos parágrafos que seguem. Aí estará, mais uma vez em consideração, a perspectiva integral do ser humano, enquanto corpo material e enquanto alma.

Por mais que eu considere que os impulsos da natureza sejam uma parcela da compatibilização com o fundamento da natureza, pois entendo que a situação que está em conformidade com o fundamento da natureza é que causa prazer e seria por isso que a satisfação dos impulsos da natureza é sentida como prazer, viver segundo esses impulsos é insuficiente para uma compatibilização com o fundamento da natureza, pois viver em conformidade com o fundamento da natureza implica buscar o desenvolvimento de todas as disposições naturais ${ }^{53}$, o que é mais do que a animalidade do homem.

Na Primeira Proposição da IaG Kant menciona: "todas as disposições naturais de uma criatura [Geschöpfes] estão destinadas a um dia se desenvolver completamente e conforme a um fim"54. Em algumas passagens Kant dá algumas direções sobre quais seriam essas disposições naturais. No ensaio Início conjectural da história humana (1786), Kant menciona duas disposições naturais, "a humanidade como espécie animal e a humanidade como espécie moral" 55 . No decorrer de sua obra, o filósofo se expressa com relação às disposições naturais em configuração diversa, como na Religião (1793), ao mencionar três disposições naturais, a saber: para a animalidade, para a humanidade e para a personalidade ${ }^{56}$; ou, ainda na Antropologia (1798), na qual também menciona três disposições e as nomeia como técnica, pragmática e moral ${ }^{57}$. Contudo, penso não ser o caso de, neste artigo, percorrer o conjunto das obras de Kant para reunir e comparar todas as menções às disposições naturais, até porque, na Religião, Kant mesmo faz a ressalva após listar três disposições naturais de que haveria outras das quais ele ali não tratou ${ }^{58}$.

Pelo que me foi dado pesquisar sobre isso, considero que a abordagem do $M A M$ pode ser entendida como englobando as demais. As que citam uma divisão tripartite ainda consideram as duas do $M A M$ como extremos e entre elas inserem um híbrido de animalidade e uso (patológico) da razão. Demais menções isoladas a uma disposição natural podem ser inseridas em um dos dois grupos citados no $M A M$. A disposição para agir moralmente apenas os seres racionais possuem. Mas a razão não é utilizada apenas no agir moral. O homem pode fazer um uso instrumental da razão. Nesse sentido, entendo que as demais especificidades mencionadas em algumas definições tripartidas como uma disposição natural híbrida animal/racional talvez possa ser resumida a uma 
disposição ainda animal, mas como o ser em questão possui razão, tem a possibilidade de a utilizar para perseguir de uma forma mais refinada (ou mais eficiente, calculada) sua animalidade, ou, ainda, "uma disposição animal simplesmente se desdobra, mas o homem racional usa de suas próprias disposições, pode transformá-las em objeto de sua própria ação"59.

Entendo que se pode considerar (ao menos para uma exposição como a presente sem que essa opção cause prejuízo conceitual) as duas perspectivas básicas das disposições naturais, para a animalidade e para a humanidade e é assim que padronizarei daqui em diante. A disposição para a animalidade visando à manutenção da vida enquanto indivíduo e espécie (com as várias implicações dessa busca) e a disposição para agir moralmente.

O processo do nível mais básico ao nível mais elevado não implica sair definitivamente de um estado e adentrar no outro. Apesar da possibilidade de um progresso (em direção ao uso da razão) tanto em termos do indivíduo quanto em termos de espécie, o ser humano ainda retorna continuamente às perspectivas meramente animais, aos prazeres meramente animais. A $K p V$ nos diz que uma vez alcançado o uso livre da razão por um sujeito, não é por isso que se pode pressupor a partir disso que esse mesmo sujeito agirá por dever todas as demais vezes. Bem como, por fazer parte da natureza humana, o prazer no agradável não se extinguirá quando em situação de deleite somente porque esse sujeito alcançou o desenvolvimento da outra perspectiva mais nobre de suas disposições naturais, apesar de que esse poderá mais facilmente domesticar suas inclinações.

Kant utiliza um conjunto de termos como especificidades de disposições naturais quando trata da forma mais básica de disposição natural, termos como a propensão ${ }^{60} \mathrm{e}$ subdivisões como a inclinação ${ }^{61}$ e o instinto. Além disso, ainda que com baixa frequência, utiliza complementos como em toscas disposições ${ }^{62}$, ou ainda em inclinação refinada ${ }^{63}$. Nesse primeiro grupo de disposições naturais, Kant chega a admitir que pode ocorrer em especificações dessa disposição natural um enxerto de vícios (como, por exemplo, a gula e a luxúria). Contudo, parece reservar ao grau mais elevado de disposições naturais como uma especificação dela apenas a receptividade (ou suscetibilidade) [Empfänglichkeit] para com o respeito, o que pode colaborar para a argumentação em favor da consideração de uma desvinculação da faculdade de apetição em relação ao prazer. A disposição natural nesse caso mais nobre seria apenas para a receptividade ao respeito, e não para com um objeto ou ação em específico.

Ambos os grupos de disposições naturais teriam uma função tendo-se em vista uma perspectiva mais ampla (para além do próprio indivíduo ou mesmo para além de situações contingentes). Na Quarta Proposição da $I a G$, o filósofo menciona que disposições as quais nos são naturais, mesmo não sendo as disposições que visam à moralidade ${ }^{64}$, toscas disposições, também essas colaboram para o desenvolvimento do plano maior e oculto da natureza. Nesse sentido, convida Kant: "agradeçamos, pois, à natureza a intratabilidade, a vaidade que produz a inveja competitiva, pelo sempre insatisfeito desejo de ter e também de dominar!"65

A Reflexão 571 nos diz que "visto que o comprazimento é o fundamento das apetições e atividades, assim ele é a direção das forças e a prática da vida mesma"66. Com isso, é ocasião propícia a se perceber que mesmo o sentimento de vida animal (o prazer no agradável) possui um lugar no plano oculto da natureza, "a natureza certamente não colocou instintos e capacidades em uma criatura viva para que devessem ser combatidos e reprimidos"67. Se o fosse, tendo a considerar que a situação que causa o sentimento de vida animal iria ser sentido pelo animal (racional e irracional) unicamente como desprazer, sentindo o impedimento da vida, e não também 
como prazer, em uma promoção da vida. Kant chega a mencionar que "as inclinações naturais, consideradas em si mesmas, são boas, isto é, irrepreensíveis, e pretender extirpá-las não só é vão, mas também é prejudicial e censurável"68.

Há um caráter paradoxal nas disposições naturais, reconhecidamente em vários momentos do texto kantiano, na $I a G$, na $K U$, na $M A M$, entre outros, e esse caráter paradoxal se deve em parte ao fato de que as disposições naturais para a animalidade, cuja concordância pelo corpo é sentido como um deleite, "não foram colocadas no homem tendo em vista o estado moral [gesitten Zustand]"69, em direção ao qual o ser humano caminha, "mas apenas a manutenção da espécie humana enquanto espécie animal"70, o que precisa ser mantida para que sobreviva até chegar ao uso livre da razão e, mesmo depois. Com uma constituição tal que comporta ambas as perspectivas de disposições naturais, "o estado civilizado [civilisierte Zustand] entra, portanto, em conflito com esse último [o estado moral]"71. Haveria um caminho para sanar esse conflito. Tal conflito "poderia ser desfeito apenas com uma constituição civil perfeita (o objetivo mais alto da cultura)"72, estágio esse no qual o ser humano estaria a utilizar plenamente a disposição mais característica de sua espécie e que, como tal, faz parte do plano da natureza que seja desenvolvida, a razão. "No momento, esse espaço intermediário é ocupado normalmente com vícios e suas conseqüências, ou seja, com diversas formas de miséria humana"73.

Como nos diz o $\S 83$ da $K U$, além de a natureza não ter poupado o ser humano de "seus efeitos destrutivos como a peste, a fome, as inundações, o gelo, o ataque de outros animais"74, ainda nos colocou como disposições naturais uma soma de impulsos contraditórios. Inerente a isso, enquanto não alcançarmos com um uso livre da razão (e não seguindo apenas as inclinações) uma constituição civil perfeita, encontrar-nos-emos submetidos a tormentos que o indivíduo inventa para si e para os outros. Assim, pode até parecer "muito errôneo pensar que a natureza o tomou [o ser humano] como seu preferido e o favoreceu em detrimento de todos os outros animais"75. O ser humano, apesar de sua especificidade única de poder vir a tomar as próprias decisões para além de uma necessidade empírica, de uma propensão, e encontrar em si mesmo, em sua própria razão a causalidade da ação sem a observação de prazer ou desprazer advindos disso, ele, ainda assim, é parte da natureza e a ela está submetido enquanto fenômeno.

Aqui me chama a atenção a consideração de que, no contexto da discussão sobre disposições naturais, aborda-se na perspectiva de que a natureza, da qual faz parte o ser humano, inseriu nele disposições naturais, entre as quais, uma disposição para a humanidade, para o uso da razão. Kant mesmo se expressa desse modo, menciona que $a$ natureza deu ao homem a razão ${ }^{76}$. Retomo que em Kant, no caso do ser humano, a alma é entendida como um princípio imaterial dotado de razão. A natureza seria a responsável pela constituição do princípio imaterial também? Que se fale de um tecnólogo muito mais poderoso que o homem, de um "espírito infinito que é o criador e conservador"78 do mundo, ou que se atribua a organização à natureza, à "alma ou [a] Deus, só se tem a escolha do arquiteto"79.

Por mais que se esteja aqui falando em termos de disposições naturais, ou, ainda, de um plano (oculto) da natureza, não se pode atribuir à natureza culpa no caso de o ser humano seguir as disposições naturais para a animalidade. Ou, ainda, há de ficar claro que "o ente racional de cada ação contrária à lei [...], ainda que ela como fenômeno seja no passado suficientemente determinada e, nessa medida, necessária, pode com direito dizer que ele poderia tê-la evitado"80. Da mesma forma, não se pode atribuir à natureza o mérito em caso de se seguir as disposições naturais para a moralidade ${ }^{81}$. Ter um conjunto de disposições naturais não faz com que o ser humano, uma vez posto em movimento, execute as ações previsivelmente. O ser humano não é 
apenas corpo material, possui um princípio imaterial dotado de razão, possui uma relação com o espírito, que nos possibilita tomarmos consciência de nossa condição suprassensível.

Ser um animal que possui espírito é, a propósito, o que faz com que possa ser capaz de uma experiência do sublime, por exemplo, haja vista que tal experiência pressupõe em seu início um sentimento de desprazer que precisa ser superado, suportar o abalo, superar o temor do abismo no qual a imaginação teme perder-se ${ }^{82}$. É em seu início um sentimento de desprazer porque "considerado subjetivamente é contrário a fins, objetivamente, porém, é necessário à avaliação da grandeza, por conseguinte conforme a fins [...] com respeito à destinação inteira do ânimo"83. Nessa ocasião, "torna-nos intuível a superioridade da determinação racional de nossas faculdades de conhecimento sobre a faculdade máxima da sensibilidade"84. Não por acaso o sentimento de vida humano e o sentimento de vida espiritual só são possíveis entre seres humanos, ou seja, que conciliam um corpo material e um princípio imaterial dotado de razão.

Para que o homem possa agir livremente, sair da rudeza animal, a natureza teria atribuído a razão ao homem. Com isso, o homem tem condições de não ser dominado pelas inclinações. Mas a passagem da rudeza da animalidade para um agir livre não se inicia com um cenário somente atrativo, implica superação inclusive do medo do novo cenário, assumindo o controle do que antes ficava a cargo somente da natureza. Essa superação do medo, ou também, esse não atrativo no processo de mudança, lembra o caso de toda experiência do sublime. Sem a superação do medo não se experencia o sublime. No caso da passagem da rudeza da animalidade para um agir livre, Kant menciona:

a história da natureza inicia com o bom [vom Guten], [...], a história da liberdade inicia com o mau [vom Bösen], [...]. Para o indivíduo, que no uso de sua liberdade tem em vista apenas a si mesmo, aquela mudança foi uma perda, para a natureza, cujos fins dizem respeito ao homem enquanto espécie, foi um ganho ${ }^{85}$.

O homem, ao deixar de seguir os impulsos da natureza estaria com isso propiciando um ganho para a natureza, ou, ainda, talvez se possa dizer que estaria também de acordo com o plano oculto da natureza que dotou o homem de razão para que ele a desenvolvesse.

$\mathrm{O}$ instinto permite, proíbe, é útil, pressente, o instinto instrui os desejos ${ }^{86}$, mas ficar nessa esfera não é satisfazer nem mesmo a natureza, que brinda com o tédio ao que satisfaz os impulsos animais. Recusar os impulsos é parte do plano da natureza, e não uma recusa do plano da natureza. Apesar da consideração de que as inclinações "relativamente à nossa determinação como espécie animal é completamente conforme a fins" ${ }^{87}$ satisfazê-las não basta.

\section{CONSIDERaÇões finais}

A relação de partes e do todo pensada em corpos como seres vivos talvez possa ser assim extrapolada, ao menos em termos de como se, para o todo do qual os próprios seres vivos fazem parte ${ }^{88}$, como, por sinal, Kant chegou a considerar, assim entendo, em seus últimos textos não publicados em vida, embora polêmicos, chegando a abordar uma perspectiva de alma do mundo (Weltseele).

Além disso, os três modos de comprazimento, isto é, esses três modos de integração do vivo ao todo do qual faz parte estão indissociáveis da alma, que é 
condição para se falar em termos de vivo. Como nos disse Rohden, tudo o que se opera na alma corresponde a uma ideia plena de vida e procura realizar-se inclusive corporalmente ${ }^{89}$.

Sendo a natureza quem organizou e estruturou o animal, o dotou de razão segundo um seu plano oculto, a alma também é posta no animal pela natureza, e é parte da natureza, e tendo a alma o critério de manter ou dispersar uma representação de acordo com a concordância com um plano, a alma parece estar em uma mais íntima conexão, ou, ainda, uma mais clara consciência do plano oculto da natureza do que o animal, mesmo o racional, consegue alcançar.

Essa noção do que concorda e do que discorda desse plano oculto da natureza deve ser procurado no princípio vital, na alma, não na matéria enquanto tal. Trata-se de uma alma que sente, uma alma de algum modo consciente do plano oculto da natureza, de acordo com o qual estabelece o critério para o que sentimos no corpo como um prazer e como um desprazer, alma que orienta, cria (representações), desfaz, move mais do que um pé, move a natureza, move o rumo da história.

\section{REFERÊNCIAS}

KANT, Immanuel. Gesammelte Schriften. Hrsg.: Bd. 1-22 Preussische Akademie der Wissenschaften, Bd. 23 Deutsche Akademie der Wissenschaften zu Berlin, ab Bd. 24 Akademie der Wissenschaften zu Göttingen. Berlin 1900ff.

. A Religião nos Limites da Simples Razão. Tradução de Artur Morão. Lisboa: Edições 70, 1992.

. Antropologia de um Ponto de vista Pragmático. Trad. Clélia Aparecida Martins. São Paulo: Iluminuras, 2006.

. Crítica da Faculdade do Juízo. Trad. António Marques e Valerio Rohden. Segunda ed. Rio de Janeiro: Forence Universitária, 2010.

. Crítica da Razão Prática. Edição bilíngue. Trad. Valerio Rohden. São Paulo: Martins Fontes, 2003.

. Crítica da Razão Pura. Trad. Fernando Costa Matos. Petrópolis, RJ: Editora Vozes, Bragança Paulista, SP: Editora Universitária São Francisco, 2012.

Critique of Judgement. Trans. by James Meredith. Oxford University Press, 2007.

Critique of the Power of Judgment. Trans. by Paul Guyer and Eric Matthews. Cambridge: Cambridge University Press, 2001.

Ideia de uma História Universal de um Ponto de Vista Cosmopolita. Org. Ricardo Terra.

Trad. Rodrigo Naves e Ricardo Terra. $3^{\mathrm{a}}$ ed. São Paulo: Martins Fontes, 2011.

Início conjectural da história humana. Trad. Joel Thiago Klein. ethic@ Florianópolis v. 8, n. 1 Jun 2009, p. 157 - 168.

- Metafísica dos costumes. Trad. [primeira parte] Clélia Aparecida Martins; [segunda parte] Bruno Nadai, Diego Kosbiau e Monique Hulshof. Petrópolis, RJ: Vozes; Bragança Paulista, SP: Editora Universitária São Francisco, 2013.

. Metaphysical foundations of natural science. Trans. and ed. by Michael Friedman. Cambridge: Cambridge University Press, 2004.

. Sonhos de um visionário explicados por sonhos da metafísica. Trad. Joãosinho Beckenkamp. In. KANT, Immanuel. Escritos pré-críticos. São Paulo: Editora da UNESP, 2005, p. $141-218$.

ADELUNG, J. C. "Wohlgefallen". In: Grammatisch-Kritisches Wörterbuch der Hochdeutschen Mundart. 1. Aufl. Leipzig 1774-1786, 5 Bde.; 2. Aufl. Leipzig 1793-1801, 4 Bde., Supplementband 1818.

CAYGILL, Howard. A Kant Dictionary. Oxford, UK: Blackwell Publishers, 1995.

DÖRFLINGER, Bernd. A ideia de Kant de um sentimento intuitivo no contexto de sua teoria do organismo. In. MARQUES, Ubirajara Rancan de Azevedo (Org.). Kant e a biologia. São 
Paulo: Editora Barcarolla, 2012.

FALDUTO, Antonino. The Faculties of the Human Mind and the Case of Moral Feeling in Kant's Philosophy. Berlín/Boston, De Gruyter (Kantstudien- Ergänzungshefte), 2014.

FERREIRA, Manuel J. Carmo. O prazer como expressão do absoluto em Kant. No $2{ }^{\circ}$ Centenário da Critica do Juízo. In AA.VV, Pensar a Cultura Portuguesa: Homenagem a Francisco da Gama Caeiro, Lisboa, Colibri/ Dep. de Filosofia da FLUL, 1993, pp. 391-402.

GIANNOTTI, José Arthur. Kant e o espaço da história universal. In. KANT, I. TERRA, Ricardo (org.). Ideia de uma história universal de um ponto de vista cosmopolita. $3^{\mathrm{a}}$ ed. São Paulo: Editora WMF Martins Fontes, 2011, p. 107 - 171.

HAMM, Christian. A fusão de campos semânticos: o exemplo de einsehen - verstehen begreifen. In: PINZANI, Alessandro. ROHDEN, Valerio (Orgs.). Crítica da Razão Tradutora: sobre a dificuldade de traduzir Kant. Florianópolis: NEFIPO, 2010. Nefiponline.

HECK, José N. Da razão prática ao Kant tardio. Porto Alegre: EDIPUCRS, 2007.

KLEIN, Joel Thiago. A sociabilidade insociável e a antropologia kantiana. Revista de Filosofia Aurora. Curitiba, v. 25, n. 36, p. 265-285, jan./jun. 2013.

LEBRUN, Gérard. Kant e o Fim da Metafísica. Tradução: Carlos Alberto Ribeiro de Moura. $2^{\text {a }}$ Ed. São Paulo: Martins Fontes, 2002.

MARQUES, António. Kant's Third Critique: What the Concept of 'Gemüt' Brings to the Concept of Reason. In: V. Gerhardt, R.P. Horstmann e R. Schumacher (orgs.). Kant und die Berliner Aufklärung. Akten des IX. Internationalen Kant-Kongresses. Berlin, 2001, vol. III, 582-583.

NAHRA, C. L. A Vida, os propósitos da natureza e por que as coisas no mundo existem. Principios, v. 23, 2016. p. 193-205.

PEREZ, Daniel Omar. O significado da natureza humana em Kant. In: SANTOS, Leonel Ribeiro dos (Coord.). et al. Was ist der Mensch? Que é o Homem? Centro de Filosofia da Universidade de Lisboa, Lisboa, 2010, p. 207-218.

ROHDEN, Valerio. A força da faculdade apetitiva como prática da virtude em Kant. In: HOBUSS, João (Org.). Ética das virtudes. Florianópolis: Editora da UFSC, 2011.

ROHDEN, Valerio. As ideias como formas de vida da Razão. In: SANTOS, Leonel Ribeiro dos (Coord.). et al. Was ist der Mensch? Que é o Homem? Centro de Filosofia da Universidade de Lisboa, Lisboa, 2010, p. 337-346.

ROHDEN, Valerio. Atualidade da filosofia moral de Kant, desde a perspectiva de sua crítica a um solipsismo prático. Cadernos IHU Ideias, São Leopoldo, Ano 2, nº 23, 2004, p. 1-22.

ROHDEN, Valerio. Viver segundo a idéia de natureza. In. BORGES, Maria de Lourdes; HECK, José (Orgs.). Kant: liberdade e natureza. Florianópolis: Ed. da UFSC, 2005, p. 233-248.

WOOD, Allen W. KANT. Trad. Delamar José Volpato Dutra. Porto Alegre: Artmed, 2008.

\section{Notas}

1 ROHDEN, V. Nota 22. In;. KANT, I. KU. Trad. 2010, p. 49.

2 ROHDEN, V. In. KANT, I. KU. Trad. 2010, p. 09.

3 Adotarei o termo "comprazimento" como correspondente a "Wohlgefallen". A justificativa para essa opção será exposta no decorrer do artigo.

4 KANT, I. KU 05: 205-207.

5 KANT, I. KU. Trad. 2010, p. 54.

6 Sobre essa compreensão de Wohlgefallen, conferir ADELUNG, J. C. "Wohlgefallen". In: Grammatisch-Kritisches Wörterbuch der Hochdeutschen Mundart. 1. Aufl. Leipzig 1774-1786, 5 Bde.; 2. Aufl. Leipzig 1793-1801, 4 Bde., Supplementband 1818, p. 1596.

7 Ainda que não se possa dizer que Kant necessariamente o tenha utilizado no que concerne a esse verbete em especial.

8 Cf, por exemplo: KANT, I. KU. AA, 5: 198. Trad. 2010, p. 42.

ROHDEN, V. Nota 22. In: KANT, I. KU. Trad. 2010, p. 49.

9 Cf. MARQUES, António. Kant's Third Critique: What the Concept of 'Gemüt' Brings to the 
Concept of Reason. In: V. Gerhardt, R.P. Horstmann e R. Schumacher (orgs.). Kant und die Berliner Aufklärung. Akten des IX. Internationalen Kant-Kongresses. Berlin, 2001, vol. III, 582-583.

10 ROHDEN, V. Nota 22. In: KANT, I. KU. Trad. 2010, p. 49.

11 KANT, I. KrV. Trad. 2012, p. 292. Cf. também, KANT, I. RGV. Trad. 1992, p. 385 nota 18, bem como KANT, I. KU. Trad. 2010, p. 50.

12 Ao se referir à ambiguidade de sua época, inerente ao uso inapropriado do termo absoluto, Kant menciona: "como a perda de um conceito de grande aplicação na filosofia especulativa não pode ser indiferente para o filósofo, espero que a determinação e a cuidadosa conservação da expressão a que o conceito é inerente também não lhe sejam indiferentes" (KANT, I. KrV. Trad. 2012, p. 293).

13 KANT, I. RGV. Trad. 1992, p. 51.

14 ROHDEN, Valerio. A força da faculdade apetitiva como prática da virtude em Kant. In: HOBUSS, João (Org.). Ética das virtudes. Florianópolis: Editora da UFSC, 2011, p. 178.

15 Cf. ROHDEN, Valerio. Interesse da razão e liberdade. São Paulo: Editora Ática, 1981.

16 ROHDEN, V. Nota 22. In: KANT, I. KU. Trad. 2010, p. 49.

17 Paul Guyer em nota de rodapé em sua tradução da $K U$ para a língua inglesa, menciona por ocasião do §5: "Complacenz, i.e., Latin complacentia, which Kant often gives as an equivalent of Lust" (GUYER, Paul. Nota C do §5. In:. KANT, I. KU. Trad. 2000, p. 95).

18 "Nós só temos um sentimento, mas diversas sensações" (KANT, I. Refl. 606. Tradução provisória de Valerio Rohden e Daniel Omar Perez).

19 KANT, I. Refl. 6871. AA, 19: 187; KANT, I. Refl. 445; KANT, I. Refl. 619.

20 Até porque, "o uso que Kant faz de conceitos filosóficos - tanto aqueles tirados da linguagem corrente da época como os 'termos técnicos' da própria disciplina - foi de extrema meticulosidade. Isso significa que vemos só muito raras as vezes em que um termo, uma vez introduzido por Kant no seu discurso filosófico, muda o seu significado ou vem sendo substituído, conforme ao contexto, por outro termo supostamente melhor, mais preciso ou mais elegante" (HAMM, Christian. A fusão de campos semânticos: o exemplo de einsehen - verstehen - begreifen. In: PINZANI, Alessandro. ROHDEN, Valerio (Orgs.). Crítica da Razão Tradutora: sobre a dificuldade de traduzir Kant. Florianópolis: NEFIPO, 2010. Nefiponline, p. 55).

21 LEBRUN, Gérard. Kant e o Fim da Metafísica. Tradução: Carlos Alberto Ribeiro de Moura. $2^{\mathrm{a}}$ Ed. São Paulo: Martins Fontes, 2002, p. 427.

22 Nesse momento da $K U$, Kant trata da Analítica do Belo. Com isso, chamo a atenção para o fato de não estar mencionado entre os modos de comprazimento o sublime (das Erhabene), no qual o autor se deterá em momento posterior. No entanto, entendo que apesar de não mencionado, o modo de comprazimento no sublime pode ser incluído juntamente com o do belo, mesmo guardando as distinções entre as duas circunstâncias, mas, em razão de que "o belo concorda com o sublime no fato de que ambos aprazem por si próprios; ulteriormente, no fato de que ambos não pressupõe nenhum juízo de reflexão; consequentemente, o comprazimento não se prende a uma sensação como a do agradável, nem a um conceito determinado como o comprazimento no bom" (KANT, I. KU. Trad. 2010, p. 89).

23 KANT, I. KU. Trad. 2010, p. 54.

$24 \mathrm{Ou}$, ainda, "como uma graça que a natureza teve para nós o fato de ela ter distribuído com tanta abundância, para além do que é útil, ainda a beleza e o encanto" (KANT, I. KU. Trad. 2010, p. 223).

25 KANT, I. KU. Trad. 2010, p. 55.

26 KANT, I. KU. Trad. 2010, p. 113.

27 Cf, sobre a comoção, a nota de Rohden menciona que o termo em questão remete a uma emoção violenta, comoção, commovere e não a uma simples emoção. Cf. também a afirmação de Kant de que "o sublime apraz". Apesar disso, a satisfação no sublime é negativa (respectivamente: ROHDEN, V. Nota 48. In: KANT, I. KU. Trad. 2010, p. 69. KANT, I. KU. Trad. 2010, p. 93 e também p. 115).

28 Cf. KANT, I. MS. Trad. 2013, p. 22/23. 
29 KANT, I. KU. Trad. 2010, p. 124.

30 “[...] todo deleite, mesmo que seja ocasionado por conceitos que despertam idéias estéticas, é sensação animal, isto é, corporal" (KANT, I. KU. Trad. 2010, p. 179).

31 "É fácil de decidir que tipo de valor a vida tem para nós, no caso desse ser avaliado simplesmente segundo aquilo que se goza [...]. Esse valor reduz-se a zero" (KANT, I. KU. Trad. 2010, p. 274).

32 KANT, I. IaG. Trad. 2011, p. 06.

33 KANT, I. IaG. Trad. 2011, p. 06.

34 KANT, I. IaG. Trad. 2011, p. 06.

35 KANT, I. IaG. Trad. 2011, p. 05.

36 FERREIRA, Manuel J. Carmo. O prazer como expressão do absoluto em Kant. No 2. ${ }^{\circ}$ Centenário da Crítica do Juízo. In: AA.VV, Pensar a Cultura Portuguesa: Homenagem a Francisco da Gama Caeiro, Lisboa, Colibri/ Dep. de Filosofia da FLUL, 1993, p. 394.

37 ROHDEN, Valerio. Viver segundo a idéia de natureza. In: BORGES, Maria de Lourdes; HECK, José (Orgs.). Kant: liberdade e natureza. Florianópolis: Ed. da UFSC, 2005, p. 235.

38 ROHDEN, Valerio. Viver segundo a idéia de natureza. In: BORGES, Maria de Lourdes; HECK, José (Orgs.). Kant: liberdade e natureza. Florianópolis: Ed. da UFSC, 2005, p. 235.

39 No original, se lê: "Lust und Unlust machen allein das absolute aus, weil sie das Leben selbst sind" (KANT, I. Refl. 4857. AA, 18: 11.18-19). A tradução utilizada é de Valerio Rohden, no ensaio: Viver segundo a idéia de natureza. In: BORGES, Maria de Lourdes; HECK, José (Orgs.). Kant: liberdade e natureza. Florianópolis: Ed. da UFSC, 2005, p. 234.

40 KANT, I. KrV. Trad. 2012, p. 292.

41 KANT, I. KrV. Trad. 2012, p. 292.

42 A título de prudência, no entanto, menciono que Ferreira considera que não se pode descartar a possibilidade de que tal anotação possa vir a se configurar como "uma eventual citação sem indicação de autoria" (FERREIRA, Manuel J. Carmo. O prazer como expressão do absoluto em Kant. No 2. ${ }^{\circ}$ Centenário da Crítica do Juízo. In: AA.VV, Pensar a Cultura Portuguesa: Homenagem a Francisco da Gama Caeiro, Lisboa, Colibri/ Dep. de Filosofia da FLUL, 1993, pp. 392).

43 O título dessa seção faz uma referência direta ao título do ensaio de Rohden de 2005, o qual remete à Refl. 6658 .

44 KANT, I. KU. Trad. 2010, p. 124.

45 Cf. Refl. 158a (KANT, I. Ref. AA. 15: 57. 04-19). Cf. também, sobre o contexto dessa discussão referente a faculdades básicas da alma, a abordagem de Falduto no item 1.3 The 1773/1775 Berlin Academy Prize Competition: Examen des deux facultés primitives de l'ame, celle de connoître et celle de sentir, em FALDUTO, 2014.

46 ROHDEN, Valerio. As ideias como formas de vida da Razão. In: SANTOS, Leonel Ribeiro dos (Coord.). et al. Was ist der Mensch? Que é o Homem? Centro de Filosofia da Universidade de Lisboa, Lisboa, 2010, p. 341.

47 ROHDEN, Valerio. As ideias como formas de vida da Razão. In: SANTOS, Leonel Ribeiro dos (Coord.). et al. Was ist der Mensch? Que é o Homem? Centro de Filosofia da Universidade de Lisboa, Lisboa, 2010, p. 341.48 HECK, José N. Da razão prática ao Kant tardio. Porto Alegre: EDIPUCRS, 2007, p. 223.

49 KANT, I. Refl. 6658. Tradução: ROHDEN, Valerio. In: BORGES, Maria de Lourdes; HECK, José (Orgs.). Kant: liberdade e natureza. Florianópolis: Ed. da UFSC, 2005, p. 233.

50 ROHDEN, Valerio. Viver segundo a ideia de natureza. In: BORGES, Maria de Lourdes; HECK, José (Orgs.). Kant: liberdade e natureza. Florianópolis: Ed. da UFSC, 2005, p. 235.

51 ROHDEN, Valerio. Viver segundo a ideia de natureza. In: BORGES, Maria de Lourdes; HECK, José (Orgs.). Kant: liberdade e natureza. Florianópolis: Ed. da UFSC, 2005, p. 236.

52 "O cosmos antigo era um mundo humano, estético. Cícero e Kant pensaram-no como mundo moral, ou seja, como tarefa de todos nós em conjunto, expressa pela idéia prática" 
(ROHDEN, Valerio. Viver segundo a ideia de natureza. In: BORGES, Maria de Lourdes; HECK, José (Orgs.). Kant: liberdade e natureza. Florianópolis: Ed. da UFSC, 2005, p. 248).

53 Faz-se salutar mencionar que minha abordagem presente restringe-se às disposições naturais em relação aos corpos (como matéria organizada), e não a um fundamento inato em relação às representações elementares do conhecimento (formas de intuição e formas de pensamento).

54 KANT, I. IaG. Trad. 2011, p. 05. Saliento o uso do termo criatura, bem como, logo na Segunda Proposição, Kant faz constar entre parênteses, ao lado de "homem", a observação: "única criatura racional sobre a Terra", uma vez que, em outra oportunidade (Refl. 4136), Kant menciona que o termo criatura não se aplicaria aos seres que agem livremente. "Man nennet Steine nicht Geschöpfe, weil sie ihre Form nicht von der Schopfung haben, aber wohl Pflanzen. Die thiere nennt man Creaturen. Frey handelnde Wesen werden nicht Creaturen genannt" (KANT, I. Refl. 4136. AA. 17: 429.22-23).

55 KANT, I. MAM. Trad. 2009, p. 167, nota 5.

56 KANT, I. RGV. Trad. 1992, p. 34.

57 KANT, I. Anth. Trad. 2006, p. 216 - 219.

58 KANT, I. RGV. Trad. 1992, p. 34. Cf. também PEREZ, Daniel Omar. O significado da natureza humana em Kant. In: SANTOS, Leonel Ribeiro dos (Coord.). et al. Was ist der Mensch? Que é o Homem? Centro de Filosofia da Universidade de Lisboa, Lisboa, 2010, p. 207-218.

59 GIANNOTTI, José Arthur. Kant e o espaço da história universal. In: KANT, I. TERRA, Ricardo (org.). Ideia de uma história universal de um ponto de vista cosmopolita. $3^{\mathrm{a}}$ ed. São Paulo: Editora WMF Martins Fontes, 2011, p. 143.

60 "A possibilidade subjetiva do surgimento de um certo desejo, que precede a representação de seu objeto, é propensão (propensio)". Quando se conhece o objeto do desejo, o "desejo sensível que serve de regra (hábito) ao sujeito chama-se inclinação (inclinatio)". Já "a coação interna da faculdade de desejar para possuir esse objeto, antes de conhecê-lo, é instinto (como impulso de acasalamento ou impulso paternal dos animais de proteger suas crias etc.)" (KANT, I. Anth. Trad. 2006, p. 163).

$61 \mathrm{O}$ conjunto de inclinações Kant denomina solipsismo. Sobre isso, cf. KANT, I. KpV. Trad. 2003, p. 253, bem como ROHDEN, Valerio. Atualidade da filosofia moral de Kant, desde a perspectiva de sua crítica a um solipsismo prático. Cadernos IHU Ideias, São Leopoldo, Ano 2, no 23, 2004, p. 1-22.

62 KANT, I. IaG. Trad. 2011, p. 09.

63 Como em KANT, I. KU. Trad. 2010, p.143.

64 Nesse sentido, discordo de Wood quando ele menciona que "agir a partir de nossa propensão à insociável sociabilidade é algo que fazemos livremente" (WOOD, Allen W. KANT. Trad. Delamar José Volpato Dutra. Porto Alegre: Artmed, 2008, pg. 146). Considero que mesmo estando em acordo com o fundamento da natureza, essa ação mencionada não é uma ação autônoma.

65 KANT, I. IaG. Trad. 2011, p. 09. Essas citadas são entendidas como inclinações que a natureza colocou na constituição do ser humano, como parte de suas disposições naturais, para que, provocado pelo antagonismo em sociedade, não se acomode em um sono eterno e busque desenvolver suas disposições naturais. Contudo, algumas linhas antes, Kant menciona paixões no contexto do debate sobre a insociável sociabilidade: ambição [Ehrsucht], tirania [Herrschsucht] e ganância [Habsucht] (sigo aqui a opção de tradução de Klein). É relevante salientar esse uso, tendo-se em vista que, segundo a Antropologia, as paixões excluem o domínio da razão, são enfermidades da alma, e, assim, talvez não fosse apropriado contar com elas para avançar da rudeza à cultura, ou ainda, para o progresso da história. Contudo, conforme expõe suficientemente Klein, pode haver ao menos duas possibilidades de resolver esse impasse: a primeira é a de considerar que a paixão em alguns indivíduos despertaria os demais a desenvolverem suas disposições naturais. Ou então, uma vez que Kant, segundo Klein, após essa passagem não voltou a mencionar as paixões com essa conotação, unicamente as inclinações, talvez se possa 
sugerir que realmente ali, naquele contexto, não era o lugar apropriado para as paixões, e que depois Kant teria se tornado mais cuidadoso com o uso desses termos nessa discussão. Klein opta pela segunda explicação. Cf. KLEIN, Joel Thiago. A sociabilidade insociável e a antropologia kantiana. Revista de Filosofia Aurora. Curitiba, v. 25, n. 36, p. 265-285, jan./jun. 2013, em especial a seção "Sociabilidade insociável: inclinação ou paixão?".

66 KANT. I. Refl. 571. Tradução provisória de Valerio Rohden e Daniel Omar Perez.

67 KANT, I. MAM. Trad. 2009, p. 167, nota 5.

68 KANT, I. RGV. Trad. 1992, p. 64.

69 KANT, I. MAM. Trad. 2009, p. 167, nota 5.

70 KANT, I. MAM. Trad. 2009, p. 167, nota 5.

71 KANT, I. MAM. Trad. 2009, p. 167, nota 5.

72 KANT, I. MAM. Trad. 2009, p. 167, nota 5.

73 KANT, I. MAM. Trad. 2009, p. 167, nota 5.

74 KANT, I. KU. Trad. 2010, p. 271.

75 KANT, I. KU. Trad. 2010, p. 271

76 KANT, I. IaG. Trad. 2011, p. 06.

77 Sobre o debate acerca de um ser inteligente como causa do mundo, em termos de um tecnólogo muito mais poderoso que o homem, cf. DÖRFLINGER, Bernd. A ideia de Kant de um sentimento intuitivo no contexto de sua teoria do organismo. In. MARQUES, Ubirajara Rancan de Azevedo (Org.). Kant e a biologia. São Paulo: Editora Barcarolla, 2012, p. 233.

78 KANT, I. TG. Trad. 2005 p. 148 (nota).

79 LEBRUN, Gérard. Kant e o Fim da Metafísica. Tradução: Carlos Alberto Ribeiro de Moura. $2^{\mathrm{a}}$ Ed. São Paulo: Martins Fontes, 2002, p. 353.

80 KANT, I. KpV. Trad. 2003, p. 345.

81 Cf. Terceira Proposição em KANT, I. IaG. Trad. 2011, p. 06-08.

82 KANT, I. KU. Trad. 2010, p. 104.

83 KANT, I. KU. Trad. 2010, p. 105.

84 KANT, I. KU. Trad. 2010, p. 103.

85 KANT, I. MAM. Trad. 2009, p. 162.

86 Cf. KANT, I. MAM. Trad. 2009, p. 162. Acrescento ainda uma passagem da Antropologia: "A natureza [...] foi sábia ao implantar em nós a disposição para a afecção, a fim de ter provisoriamente as rédeas nas mãos até que a razão alcançasse a força adequada, isto é, a fim de acrescentar ainda móbiles de estímulo patológico (sensível), que fazem inteiramente as vezes da razão, para a vivificação dos móbiles morais. Pois de resto a afecção, considerada por ela só, é sempre imprudente: ela se faz incapaz de prosseguir seu próprio fim" (KANT, I. Anth. Trad. 2006, p. 151)

87 KANT, I. KU. Trad. 2010, p. 273 s.

88 "Quando nós pensamos como se a natureza tivesse um propósito é então possível dar algum tipo de explicação sobre como seres organizados são possíveis. A vida emerge porque a natureza tem um propósito e o propósito da natureza é criar vida [...] e, especialmente, criar vida racional" (NAHRA, C. L. A Vida, os propósitos da natureza e por que as coisas no mundo existem. Principios, v. 23, 2016. p. 199 - 200).

89 ROHDEN, Valerio. As ideias como formas de vida da Razão. In: SANTOS, Leonel Ribeiro dos (Coord.). et al. Was ist der Mensch? Que é o Homem? Centro de Filosofia da Universidade de Lisboa, Lisboa, 2010, p. 341. 